\title{
COVID-19 neurotropism and implications for therapy
}

\author{
Mahasweta Das ${ }^{1,4}$, Courtney Penn ${ }^{1,4}$, Taylor Martinez ${ }^{1,4}$, Karthick Mayilsamy ${ }^{1,4}$, Andrew McGill ${ }^{1,2,4}$, Alison \\ Wiling $^{3}$, Shyam S. Mohapatra ${ }^{2,4}$, Subhra Mohapatra ${ }^{1,4}$ \\ 'Department of Molecular Medicine, University of South Florida, Morsani College of Medicine, Tampa, FL 33612, USA. \\ 2Department of Internal Medicine, University of South Florida, Morsani College of Medicine, Tampa, FL 33612, USA. \\ ${ }^{3}$ Department of Neurosurgery and Brain Repair, Center of Excellence for aging and Brain Repair, University of South Florida, \\ Morsani College of Medicine, Tampa, FL 33612, USA. \\ ${ }^{4}$ James A Haley Veterans Hospital, Tampa, FL 33612, USA.
}

Correspondence to: Dr. Subhra Mohapatra, Department of Molecular Medicine, University of South Florida, Morsani College of Medicine, Tampa, FL 33612, USA. E-mail: smohapa2@usf.edu; and Dr. Shyam S. Mohapatra, Department of Internal Medicine, University of South Florida, Morsani College of Medicine, Tampa, FL 33612, USA. E-mail: smohapat@usf.edu

How to cite this article: Das M, Penn C, Martinez T, Mayilsamy K, McGill A, Wiling A, Mohapatra SS, Mohapatra S. COVID-19 neurotropism and implications for therapy. Neuroimmunol Neuroinflammation 2020;7: 141-9. http://dx.doi.org/10.20517/2347-8659.2020.36

Received: 28 Apr 2020 First Decision: 25 May 2020 Revised: 25 May 2020 Accepted: 1 Jun 2020 Available online: 3 Jun 2020

Science Editor: Athanassios P. Kyritsis Copy Editor: Cai-Hong Wang Production Editor: Jing Yu

\begin{abstract}
The mechanism underlying the pathogenesis of severe acute respiratory syndrome coronavirus-2 (SARS-CoV-2) infection in humans is poorly understood, although the cellular receptors which facilitate the virus fusion have been identified. Although the major symptoms of the infection have been identified as acute respiratory distress, pneumonia, and fever, recently, symptoms involving nervous system dysfunctions, including encephalopathy and stroke, have been detected. Herein, we comprehensively review the evidence that SARS-CoV-2 infection involves a neurotropic mechanism including a nose-brain-lung axis suggesting implications in therapy development.
\end{abstract}

Keywords: SARS-CoV-2, nose-brain-lung axis, neurotropism

\section{INTRODUCTION}

The current global pandemic outbreak of novel severe acute respiratory syndrome coronavirus 2 (SARSCoV-2) is known for its viral tropism to the lungs, which in severe cases can lead to the fatal respiratory failure of patients who have contracted the disease. SARS-CoV-2 and SARS-CoV viruses have a 70\%-80\% homology and both enter the body through the same receptor, angiotensin converting enzyme $2(\mathrm{ACE} 2)^{[1]}$.

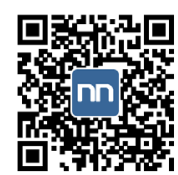


In addition to their genetic homology, the pathology that the two viruses exhibit in the clinic are highly $\operatorname{similar}^{[2]}$. In a recent report from Wuhan, China, Mao and colleagues showed that in addition to respiratory symptoms including pneumonia and acute respiratory distress syndrome (ARDS), out of 214 hospitalized COVID-19 patients 78 (36.4\%) showed neurological manifestations such as cerebrovascular diseases (5.7\%), impaired consciousness $(14.8 \%)$, and skeletal muscle injury $(19.3 \%)^{[3]}$. Six percent of COVID-19 patients have been reported to show symptoms of stroke and $15 \%$ were reported to show encephalopathy ${ }^{[4]}$. A number of symptoms such as dizziness, headache, loss of taste and smell, impaired consciousness, seizures, and nerve pain suggest a neurological connection to this viral infection.

Previously, SARS-CoV was observed in the cerebrospinal fluid of a SARS patient showing ARDS ${ }^{[5]}$. Neuropathy in a COVID-19 patient has been reported in which the patient had hyposmia and altered taste sensation ${ }^{[6]}$. Establishing the link between prior coronaviruses and their neurotropism appears to be important because there is now mounting evidence for SARS-CoV-2 neuronal abnormalities emerging as a significant symptom associated with the disease ${ }^{[7]}$. COVID-19 patients can show neurological manifestation under three situations: due to neurotropism of the virus, post-infective neurological complications or aggravated symptoms in patients with neurological co-morbidities like dementia ${ }^{[8]}$. Moreover, the neurological complications and symptoms can be central, including headache, dizziness, altered sensorium, stroke, ataxia, encephalitis, and seizuers, or peripheral, like loss of smell or taste sensation or skeletal muscle injury ${ }^{[8]}$. Herein, we review a profound neurological basis of SARS-CoV-2 infection-induced global pandemic and how the viral infection modulates the breathing of the lungs leading to fatal ARDS, to which about $50 \%-80 \%$ of the severely ill patients succumb.

\section{NEUROTROPISM OF $\beta$-CORONAVIRUSES}

The family of $\beta$-coronaviruses, to which SARS and SARS-CoV-2 belong, have been extensively studied. Several of the $\beta$-coronaviruses have been discovered within the brain (especially the brain stem), including SARS-CoV, hCoV-229E, hCov-OC43, mouse hepatitis E, and porcine hemagglutinating encephalomyelitis (HEV) coronavirus ${ }^{[5,9]}$. Middle Eastern respiratory syndrome (MERS) virus, another notable zoonotic viral outbreak in 2008-2009, that utilizes a different host receptor, DPP4, has also been discovered in the brain stem of experimental animals even in the absence of lung infection ${ }^{[10]}$, demonstrating a strong propensity for the family of $\beta$-coronaviridae to infect the brain. While ACE2 is expressed at low levels within the brain, it has been hypothesized that the "promiscuous" spike protein of $\beta$-coronaviruses may also have an unknown receptor in the brain and peripheral nerves to which the neurotropism is owed ${ }^{[10]}$.

SARS-CoV and MERS-CoV are considered important coronaviruses with the potential of nervous system damage. SARS-CoV was found to cause neurological conditions like demyelination of nerve fibers, ischemic changes of neurons, and diseases such as encephalitis, polyneuropathy, and aortic ischemic stroke $^{[11]}$. Similarly, 1 in 5 MERS-CoV patients were reported with neurological symptoms such as paralysis, ischemic stroke, loss of consciousness and Guillain Barré syndrome ${ }^{[12]}$. The presence of SARS-CoV has also been demonstrated in mice brain experimentally infected with SARS-CoV ${ }^{[13]}$. Another coronavirus, the mouse hepatitis virus type 3, can disrupt the BBB by down-regulating interferon $\beta$ which would allow virus and infected immune cells in ${ }^{[14]}$.

\section{NEURAL CONTROL OF BREATHING}

The major life-threatening symptoms of SARS-CoV-2 infection are respiratory failure and pneumonia. While pneumonia is largely an inflammatory condition of the lungs, breathing is extensively regulated by the brain. Breathing is regulated by numerous internal and external stimuli, which are integrated in the brain stem to produce the muscle movements necessary for inspiration (or inhalation), and expiration (or exhalation) [Figure 1A]. The rate and phases of the breathing pattern arise from respiratory centers 


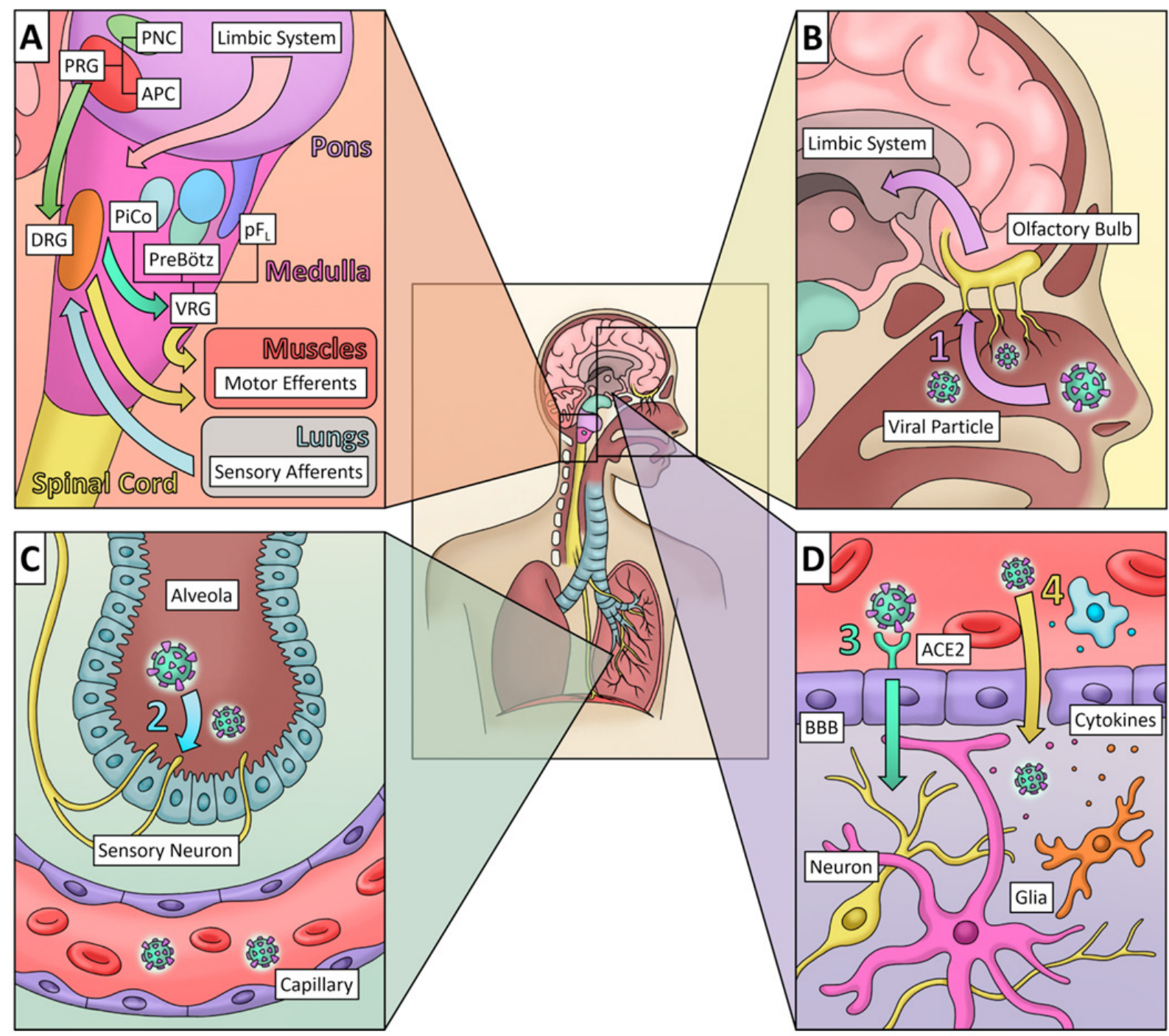

Figure 1. Respiratory centers of the brainstem and methods of viral entry into the nervous system. A: The brainstem contains the respiratory centers which integrate signals from the cortex through the limbic system and regulate breathing. Motor efferents from the brain stem innervate the diaphragm, airways, and abdominal muscles which create the movements necessary for inhalation and exhalation; B: olfactory neurons are susceptible to infection by viral particles in the nasal cavity (Route 1). These sensory neurons cross the cribiform plate and project through the olfactory tract into areas of the cortex and limbic system; C: alveoli in the lung are innervated by sensory neurons projecting up the spinal cord to the brainstem. The sensory neurons that innervate the lungs directly gather chemo- and mechano-signals from their dendrites in the lung and project them to pre-synapses in the brainstem. These neurons detect changes in oxygen and $\mathrm{CO}_{2}$, mechanical stretch, and irritants that may be inhaled into the lung. Viral particles may enter these neurons and be transported anterogradely to the respiratory centers of the brainstem (Route 2). They may also enter the bloodstream and be subsequently introduced to the brain parenchyma through the blood-brain barrier (BBB) (Routes 3 and 4); D: a viral infection in the bloodstream may cross the BBB by active transport via receptors on the surface of endothelial cells (Route 3 ) or by passive diffusion through a leaky barrier (Route 4). Immune cells in the blood and glial cells in the brain respond to infection by releasing inflammatory cytokines, which may damage the BBB and result in greater passive diffusion of the virus. Arrows indicate the direction of signal transmission (A). Arrows indicate the direction of virus movement (B, C, D). Numerals 1-4 indicate different proposed routes of viral transmission. PNC: pneumotaxic center; APC: apneustic center; PRG: pontine respiratory group; $\mathrm{pF}_{\mathrm{L}}$ : lateral parafacial nucleus; PiCo: postinspiratory complex; PreBötz: PreBötzinger complex; VRG: ventral respiratory group; DRG: dorsal respiratory group

in the pons and medulla. This control arises from neural circuits projecting from the cerebral cortex to the brainstem ${ }^{[15]}$. In addition to voluntary control of breathing, a variety of sensory pathways contribute to the breathing pattern ${ }^{[16]}$. Normal breathing consists of an inexorable active inspiration phase arising from rhythmic neural activity in the preBötzinger (preBötz) complex ${ }^{[17]}$. The preBötz is a region of the ventrolateral medulla which is active in phase with inspiration. Neurons in the preBötz project either 
directly or indirectly to motor neurons which innervate the diaphragm, intercostals, and airway muscles [Figure 1A]. Rhythmic limb movement has also been shown to modulate breathing through afferent sensory pathways ${ }^{[18]}$. Of particular interest are vagal sensory neurons expressing chemoreceptors and mechanoreceptors, which project from the lungs and airways to respiratory centers of the brainstem ${ }^{[19]}$. Due to their inherent proximity to the primary infection site, these sensory neurons present one potential mechanism by which respiratory viruses may enter the brain ${ }^{[20]}$. Expiration is passive at rest. However, active expiration may be brought on by increased $\mathrm{O}_{2}$ demand, such as respiratory distress ${ }^{[21]}$. Disinhibition or activation of neurons in the lateral parafacial nucleus $\left(\mathrm{pF}_{\mathrm{L}}\right)$, which project to expiratory premotor neurons, causes contraction of muscles, which reduces lung volume below their resting capacity ${ }^{[22]}$. This reduced lung volume after active exhalation increases the volume of the subsequent breath resulting in greater $\mathrm{O}_{2}$ delivery. A third phase, post-inspiration, may occur between the inspiration and exhalation phases. Post-inspiration is a delay of lung deflation which increases gas exchange in the lung ${ }^{[23]}$. It may originate from interneurons medial to the parafacial nucleus, referred to as the post-inspiratory complex $(\mathrm{PiCo})^{[24]}$. Thus, infection of any of these regions of the brain may lead to respiratory distress or even failure.

\section{EVIDENCE OF NEUROTROPISM OF SARS-COV-2}

It has been postulated that, like other $\beta$ coronaviruses, SARS-CoV-2 can also infect the brain by migrating from the general circulation to the cerebral microcirculation via endothelial cells which express $\mathrm{ACE} 2^{[5]}$. In a recent case study published by Poyiadji et al.$^{[25]}$, they described an acute hemorrhagic necrotizing encephalopathy that was directly attributed to SARS-CoV-2 infection and the concurrent cytokine storm induced upon infection ${ }^{[25,26]}$. Beyond isolated cases of overt severe neurological pathologies, $45 \%$ of severe cases exhibited neurologic symptoms ${ }^{[3]}$, increasing the likelihood that potential complications arising from severe SARS-CoV-2 infections may have a strong neurologic component that has yet to be described and characterized. Human coronavirus OC43 has been demonstrated to be transmitted in mice both passive diffusion of released viral particles and axonal transport ${ }^{[27]}$.

\section{Possible pathways for SARS-CoV-2 invasion of the central nervous system}

The major receptor for SARS-CoV-2, ACE2, is distributed in multiple tissues of the body. It is present in epithelial cells of alveoli and small intestine arterial and venous endothelial cells and arterial smooth muscle cells ${ }^{[28]}$ neuronal, glial and endothelial cells of the brain ${ }^{[5]}$. Low expression is observed in glomerular tubular cells. Glomerular endothelial cells, Kupffer cells, hepatocytes, spleen, thymus, lymph nodes and immune cells do not show the expression of ACE2 ${ }^{[29]}$. Similar to SARS-CoV, SARS-CoV-2 uses the spike protein $S_{1}$ to attach to the host cell ACE2 receptor ${ }^{[13,30]}$, but SARS-CoV-2 binds to the receptor with 10-20 fold higher affinity ${ }^{[30]}$. A possible explanation for this increased affinity comes from the intense work of Shang et al. ${ }^{[31]}$. By determining the crystal structure of the receptor-binding domain (RBD) of the spike protein (S1), they showed that, compared to SARS-CoV, SARS-CoV-2 receptor binding motif (RBM) contains a structural change in the ACE2-binding ridge caused by a four residue motif (residues 482-485: Gly-Val-Glu-Gly) due to which the ridge becomes more compact and forms more rigid contact with the $\mathrm{N}$-terminal helix of $\mathrm{ACE} 2^{[31]}$. In addition, changes in several other residues in the SARS-CoV-2 RBD caused higher stabilization of two virus-binding hotspots at the RBD-ACE2 interface causing higher affinity of SARS-CoV-2 to ACE2 ${ }^{[31]}$. A comparison between SARS-CoV-2 RBD subdomain-1 (S1) with the RBD glycoprotein of bat coronavirus (RaTG13) and S1 protein of SARS coronavirus showed strong but not identical homology in the spike proteins of all three CoVs which can possibly explain the high binding affinity of SARS-CoV-2 to human ACE2 receptor ${ }^{[5]}$. Ou et al. ${ }^{[32]}$ showed that the SARS-CoV-2 spike protein is less thermostable than SARS-CoV spike protein, suggesting its higher infectivity ${ }^{[32]}$.Upon binding with the ACE2, SARS-CoV-2 S protein is primed by serine protease TMPRSS $^{[33]}$. SARS-CoV-2 might be able to transmigrate to the brain via the general circulation, the 
olfactory pathway, or the peripheral neurons of the lungs. The schematic in Figure 1 shows the possible pathways of virus entry to the central nervous system (CNS).

\section{The olfactory pathway}

A proposed pathway that the virus can take to reach the brain is the olfactory pathway [Figure $1 \mathrm{~B}$ ]. Total or partial loss of smell, either by "cytokine storm" or damage of the olfactory epithelium (OE), is an early indicator of SARS-CoV-2 infection. Damage of the OE is particularly important as the cells express both ACE2 and TMPRSS2 ${ }^{[34]}$. ACE2 is highly expressed in the non-neuronal goblet/secretory cells ${ }^{[35]}$ and ciliated receptor cells of the nasal epithelium ${ }^{[5,36]}$. Upon binding with these receptors, the virus can travel through the cribriform plate to the olfactory bulb, move trans-synaptically to the cortex, and then to the brain stem ${ }^{[5]}$. The non-neuronal cells in the OE possibly serve as reservoir of the virus ${ }^{[1,34]}$. The major complication causing death in COVID-19 is respiratory failure and pneumonia. The CNS control of respiration, as described above, is an important factor in maintaining proper respiratory physiology. Failure of CNS to control the rate and depth of respiration may lead to irreversible serious consequences. Brain stem respiratory centers (RC) are the major neuronal groups controlling respiration. In a recent study Moberly et al. ${ }^{[37]}$ showed the anatomical and functional connectivity among the RC neurons, nasal epithelium and different brain regions including the olfactory bulb and limbic system ${ }^{[37]}$. Thus, damage to any segment of this network is expected to cause respiratory distress as well as emotional and behavioral dysfunction. Direct evidence of olfactory transmission of SARS-CoV was produced by Netland et al. ${ }^{[13]}$. By immunohistochemical methods they showed the presence of SARS-CoV in several brain regions of genetically modified mice including olfactory bulb, cerebral cortex, hippocampus and brain stem following intranasal infection of the virus. Most importantly, in case of low-grade infection, the virus was observed in the brain in the absence of lung infection or pneumonia ${ }^{[13]}$. There is a $60 \mathrm{~h}$ delay between virus infection and the presence of virus in the olfactory bulb ${ }^{[13]}$, and this time is probably used by the virus for replication and accumulation in the non-neuronal OE cells ${ }^{[34]}$. The subsequent transport of the virus to other regions of the brain was relatively faster, approximately $12 \mathrm{~h}-20 \mathrm{~h}^{[13]}$. However, a recent study conducted by Bao et $a l .{ }^{[38]}$ showing the respiratory transmission of the virus via liquid droplets from infected to uninfected hACE2 transgenic mice did not report any neural transmission or viral presence in the brain ${ }^{[38]}$.

\section{The respiratory neuronal pathway}

Lung-adjacent peripheral neurons may offer a second pathway for SARS-CoV-2 to enter the CNS [Figure $1 \mathrm{C}]$. Due to their proximity to the primary infection site, these neurons are highly susceptible to viral invasion. The previously mentioned porcine HEV has been visually identified by transmission electron microscopy to infect sensory dorsal root ganglia ${ }^{[39]}$ and appears to be trans-synaptically transferred to the brain stem via membrane-coated vesicles ${ }^{[40]}$. HEV shares $91 \%$ homology to hCoV-OC43, a close relative to SARS-CoV-2 ${ }^{[41]}$, which provides some evidence that SARS-CoV-2 may also invade via a similar pathway. The direct synaptic connections between these sensory nerves and the respiratory centers in mammals may prove to be important in the characteristic respiratory failure seen in severe COVID-19 patients.

\section{The circulatory pathway}

Upon infection, SARS-CoV-2 has been detected in the general circulation from which it can be transported to the cerebral circulation ${ }^{[5]}$. Endothelial cells (EC) of the blood-brain barrier (BBB) express the ACE2 receptor. The virus then binds with the receptor to enter the ECs and multiply. Eventual budding enables the virus to infect the brain parenchyma, especially the neuronal cells ${ }^{[5,42]}$, which also express ACE2 receptors. The damaged capillaries cause micro-hemorrhage, which can have fatal consequences. Once in the neurons, the viruses multiply and bud off the neurons killing the cells and infecting many more cells in the brain, which leads to functional deficits [Figure 1D]. In the case of SARS-CoV infection, Netland et al. ${ }^{[13]}$ showed that the virus causes neuronal damage without evoking a substantial inflammatory response ${ }^{[13]}$. In a small subset of severe influenza cases and various other viral infections, an associated cytokine storm 
Table 1. Currently recruiting clinical trials involving $\mathrm{MSCs}^{1}$

\begin{tabular}{|c|c|c|c|}
\hline $\begin{array}{l}\text { NCT number } \\
\text { (Phases) }\end{array}$ & Interventions & $\begin{array}{l}\text { Enrollment } \\
\text { (age) }\end{array}$ & Location \\
\hline $\begin{array}{l}\text { NCT04313322 } \\
\text { (Phase 1) }\end{array}$ & Wharton's Jelly MSCs & $5(18+)$ & Stem Cells Arabia, Amman, Jordan \\
\hline $\begin{array}{l}\text { NCT04336254 } \\
\text { (Phase } 1,2 \text { ) }\end{array}$ & $\begin{array}{l}\text { Allogeneic human dental pulp stem } \\
\text { cells vs. saline injection (Placebo) }\end{array}$ & $20(18-65)$ & $\begin{array}{l}\text { Renmin Hospital of Wuhan University (East Campus), } \\
\text { Wuhan, Hubei, China }\end{array}$ \\
\hline $\begin{array}{l}\text { NCT04288102 } \\
\text { (Phase 2) }\end{array}$ & $\begin{array}{l}\text { MSCs vs. } 1 \% \text { Human serum } \\
\text { albumin in saline }\end{array}$ & $90(18-75)$ & $\begin{array}{l}\text { Maternal and Child Hospital of Hubei and Huoshenshan } \\
\text { Hospital, Wuhan, Hubei, China }\end{array}$ \\
\hline $\begin{array}{l}\text { NCT04252118 } \\
\text { (Phase 1) }\end{array}$ & MSCs & $20(18-70)$ & Beijing 302 Military Hospital of China, Beijing, China \\
\hline $\begin{array}{l}\text { NCT04366271 } \\
\text { (Phase 2) }\end{array}$ & Standard of Care vs. MSC & $106(40-80)$ & Hospital Infantil Universitario Nino Jesus, Madrid, Spain \\
\hline $\begin{array}{l}\text { NCT04355728 } \\
\text { (Phase 1/2) }\end{array}$ & UCMSCs & $24(18+)$ & University of Miami, USA \\
\hline $\begin{array}{l}\text { NCT04366063 } \\
\text { (Phase } 2 / 3 \text { ) }\end{array}$ & MSC Therapy & $60(18-65)$ & Royan Institute, Tehran \\
\hline $\begin{array}{l}\text { NCT04339660 } \\
\text { (Phase } 1,2)\end{array}$ & CMSCs vs. Placebo & $30(18-75)$ & $\begin{array}{l}\text { Puren Hospital Affiliated to Wuhan University of Science and } \\
\text { Technology, Wuhan, Hubei, China }\end{array}$ \\
\hline $\begin{array}{l}\text { NCT04392778 } \\
\text { (Phase 1/2) }\end{array}$ & MSCs vs. Saline Control & $30(40-60)$ & Istinye University, Istanbul, Turkey \\
\hline $\begin{array}{l}\text { NCT04390139 } \\
\text { (Phase 1/2) }\end{array}$ & Excel-UMC-Beta vs. Placebo & $30(18-75)$ & Hospital DE Bellvitge, Barcelona, Spain \\
\hline $\begin{array}{l}\text { NCT04371393 } \\
\text { (Phase 3) }\end{array}$ & Remestemcel-L vs. Placebo & $300(18+)$ & $\begin{array}{l}\text { University of Southern California, Los Angeles, CA and Ichan } \\
\text { School of Medicine at Mount Sanai, NY, USA }\end{array}$ \\
\hline $\begin{array}{l}\text { NCT03042143 } \\
\text { (Phase } 1 / 2 \text { ) }\end{array}$ & $\begin{array}{l}\text { UCMSCs (CD362 Enriched) vs. } \\
\text { Placebo }\end{array}$ & $75(16+)$ & $\begin{array}{l}\text { Belfast Health and Social Care Trust, Royal Hospital, Northern } \\
\text { Ireland, UK }\end{array}$ \\
\hline $\begin{array}{l}\text { NCT04269525 } \\
\text { (Phase 2) }\end{array}$ & Umbilical Cord MSCs & $10(18-75)$ & $\begin{array}{l}\text { Zhongnan Hospital of Wuhan University, Wuhan, Hubei, } \\
\text { China }\end{array}$ \\
\hline $\begin{array}{l}\text { NCT04361942 } \\
\text { (Phase 2) }\end{array}$ & MSC vs. Placebo & $24(18+)$ & Hospital Universitario Rio Hortega, Valladolid, Spain \\
\hline NCT04333368 & $\begin{array}{l}\text { Umbilical cord Wharton's Jelly } \\
\text { MSCs vs. NaCl } 0.9 \%\end{array}$ & $60(18+)$ & $\begin{array}{l}\text { Hôpital Pitié-Salpêtrière and Européen Georges Pompidou, } \\
\text { Paris, France }\end{array}$ \\
\hline
\end{tabular}

${ }^{1}$ ClinicalTrials.Gov; accessed 27 May 2020. MSCs: mesenchymal stem cells

and subsequent BBB breakdown has been described as a known passive method of entry for viral particles causing acute necrotizing encephalopathy in some patients ${ }^{[43]}$.

\section{NEUROTROPISM-TARGETED COVID-19 TREATMENT APPROACH}

Thus far, there have been $\sim 300$ clinical trials registered in the National Institute of Health (www. clinicaltrials.gov) on treatments for SAR-CoV-2. Most of these trials focus on antiviral drugs, without any due consideration of the neurotropism of the virus. To our knowledge there are more than 160 antiviral agents are available ${ }^{[44]}$. Screening of these compounds with the intent to identify those that lack neurodegenerative properties or those that possess neuro-regenerative effects may be useful in identifying safe and effective drugs for SARS-CoV-2. It is interesting that one small clinical study relating to SARS$\mathrm{CoV}-2$ of the effects of mesenchymal stem cells (MSCs), which are known to exert anti-inflammatory and neuro-regenerative activities in brain disorders, showed excellent efficacy, i.e., all 7 of 7 patients showed symptom reduction in 2 days after MSC transplantation ${ }^{[45]}$. This study has provided a basis for several MSC-based either observational or phase 1-3 trials, which are currently recruiting [Table 1]. In addition, there are several other clinical trials which are registered but have not yet begun to recruit. Given the pivotal role of neuropathology of SARS-CoV-2 and neuronal control of breathing, future therapies should target neurotropism of the virus and combine anti-neuroinflammatory and neuro-regenerative features.

\section{FUTURE THERAPEUTIC IMPLICATIONS}

Several lines of evidence on coronaviruses and exploratory studies in SARS-CoV-2 have demonstrated the involvement of viral neurotropism in the brain stem respiratory center, whose components control 
breathing, but it is unclear which of these three different pathways offer a potential method of invasion for the virus, and they are not necessarily mutually exclusive. The viral entry of SARS-CoV-2 may be via circulatory in one patient and via oronasal or peripheral sensory neurons in another. Each of these pathways warrants further investigation to determine the neurotropism of SARS-CoV-2, and how these pathways may be exploited to treat patients in the future.

Also, it is evident that one particular approach that is under intense investigation is the development of potential SARS-CoV-2 treatment using MSCs, which have shown neuro-regenerative properties in several brain disorders including traumatic brain injury $(\mathrm{TBI})^{[46]}$. One of the issues in using MSCs in inflammatory conditions is that MSCs undergo apoptosis or differentiation due to cytokines being released in those inflammatory tissues. It has been reported that pretreatment of TBI animals first with an anti-inflammatory agent followed by MSC treatments significantly increases the efficacy of $\mathrm{MSCs}^{[46]}$. Whether a similar strategy would be more successful in COVID-19 remains to be elucidated. Given the pace and expansiveness of the COVID-19 super pandemic and the fact that the rebound infection may continue for several months to years or could be a seasonal respiratory virus infection similar to influenza and respiratory syncytial virus, it may be prudent to test these possibilities.

\section{DECLARATIONS}

\section{Authors' contributions}

Wrote the manuscript: Das M, Penn C, Martinez T, Mayilsamy K, McGill A

Made the illustration: Penn C

Reviewed the manuscript: Wiling A, Mohapatra SS, Mohapatra S

Approved the final version of the manuscript: All authors

\section{Availability of data and materials}

Not applicable.

\section{Financial support and sponsorship}

This work is partly supported by a University of South Florida Pandemic Response Research Network funding for COVID-19 and Veterans Affairs Merit Review grant (No. BX002668) to Dr. Subhra Mohapatra, and Research Career Scientist Awards to Dr. Subhra Mohapatra (No. IK6BX004212) and Dr. Shyam Mohapatra (No. IK6BX003778). Though this report is based upon work supported, in part, by the Department of Veterans Affairs, Veterans Health Administration, Office of Research and Development, the contents of this report do not represent the views of the Department of Veterans Affairs or the United States Government.

\section{Conflicts of interest}

All authors declared that there are no conflicts of interest.

\section{Ethical approval and consent to participate}

Not applicable.

\section{Consent for publication}

Not applicable.

\section{Copyright}

(c) The Author(s) 2020. 


\section{REFERENCES}

1. Zhou P, Yang XL, Wang XG, Hu B, Zhang L, et al. A pneumonia outbreak associated with a new coronavirus of probable bat origin. Nature 2020;579:270-3.

2. Wang Z, Yang B, Li Q, Wen L, Zhang R. Clinical features of 69 cases with coronavirus disease 2019 in Wuhan, China. Clin Infect Dis 2020; doi: 10.1093/cid/ciaa272.

3. Mao L, Wang M, Chen S, He Q, Chang J, et al. Neurological manifestations of hospitalized patients with COVID-19 in Wuhan, China: a retrospective case series study. medRxiv 2020;2020.02.22.20026500.

4. Rabin RC. Some coronavirus patients show signs of brain ailments. N Y Times, April 1 2020. https://www.nytimes.com/2020/04/01/ health/coronavirus-stroke-seizures-confusion.html

5. Baig AM, Khaleeq A, Ali U, Syeda H. Evidence of the COVID-19 virus targeting the CNS: tissue distribution, host-virus interaction, and proposed neurotropic mechanisms. ACS Chem Neurosci 2020; doi: 10.1021/acschemneuro.0c00122.

6. Li YC, Bai WZ, Hashikawa T. The neuroinvasive potential of SARS-CoV2 may play a role in the respiratory failure of COVID-19 patients. J Med Virol 2020; doi: 10.1002/jmv.25728.

7. Rodriguez-Morales AJ, Cardona-Ospina JA, Gutierrez-Ocampo E, Villamizar-Pena R, Holguin-Rivera Y, et al. Clinical, laboratory and imaging features of COVID-19: a systematic review and meta-analysis. Travel Med Infect Dis 2020; doi: 10.1016/ j.tmaid.2020.101623:101623.

8. Lahiri D, Ardila, A. COVID-19 pandemic: a neurological perspective. Cureus 2020;12:e7889.

9. Song Z, Xu Y, Bao L, Zhang L, Yu P, et al. From SARS to MERS, thrusting coronaviruses into the spotlight. Viruses 2019;11.

10. Li K, Wohlford-Lenane C, Perlman S, Zhao J, Jewell AK, et al. Middle East respiratory syndrome coronavirus causes multiple organ damage and lethal disease in mice transgenic for human dipeptidyl peptidase 4. J Infect Dis 2016;213:712-22.

11. Tsai LK, Hsieh ST, Chang YC. Neurological manifestations in severe acute respiratory syndrome. Acta Neurol Taiwan 2005;14:113-9.

12. Kim JE, Heo JH, Kim HO, Song SH, Park SS, et al. Neurological complications during treatment of Middle East respiratory syndrome. J Clin Neurol 2017;13:227-33.

13. Netland J, Meyerholz DK, Moore S, Cassell M, Perlman S. Severe acute respiratory syndrome coronavirus infection causes neuronal death in the absence of encephalitis in mice transgenic for human ACE2. J Virol 2008;82:7264-75.

14. Bleau C, Filliol A, Samson M, Lamontagne L. Brain invasion by mouse hepatitis virus depends on impairment of tight junctions and beta interferon production in brain microvascular endothelial cells. J Virol 2015;89:9896-908.

15. Butler JE. Drive to the human respiratory muscles. Respir Physiol Neurobiol 2007;159:115-26.

16. Bordoni B, Marelli F, Bordoni G. A review of analgesic and emotive breathing: a multidisciplinary approach. J Multidiscip Healthe 2016;9:97-102.

17. Yang CF, Feldman JL. Efferent projections of excitatory and inhibitory preBotzinger Complex neurons. J Comp Neurol 2018;526:1389402.

18. Shevtsova NA, Marchenko V, Bezdudnaya T. Modulation of respiratory system by limb muscle afferents in intact and injured spinal cord. Front Neurosci 2019;13:289.

19. Chang RB, Strochlic DE, Williams EK, Umans BD, Liberles SD. Vagal sensory neuron subtypes that differentially control breathing. Cell 2015;161:622-33.

20. McGavern DB, Kang SS. Illuminating viral infections in the nervous system. Nat Rev Immunol 2011;11:318-29.

21. Saini JK, Pagliardini S. Breathing during sleep in the postnatal period of rats: the contribution of active expiration. Sleep 2017;40.

22. Huckstepp RT, Henderson LE, Cardoza KP, Feldman JL. Interactions between respiratory oscillators in adult rats. Elife 2016;5.

23. Dutschmann M, Jones SE, Subramanian HH, Stanic D, Bautista TG. The physiological significance of postinspiration in respiratory control. Prog Brain Res 2014;212:113-30.

24. Anderson TM, Garcia AJ 3rd, Baertsch NA, Pollak J, Bloom JC, et al. A novel excitatory network for the control of breathing. Nature 2016;536:76-80.

25. Poyiadji N, Shahin G, Noujaim D, Stone M, Patel S, et al. COVID-19-associated acute hemorrhagic necrotizing encephalopathy: CT and MRI features. Radiology 2020; doi: 10.1148/radiol.2020201187:201187.

26. Das G, Mukherjee N, Ghosh S. Neurological insights of COVID-19 pandemic. ACS Chem Neurosci 2020; doi: 10.1021/ acschemneuro.0c00201.

27. Dube M, Le Coupanec A, Wong AHM, Rini JM, Desforges M, et al. Axonal transport enables neuron-to-neuron propagation of human coronavirus OC43. J Virol 2018;92.

28. Hamming I, Timens W, Bulthuis ML, Lely AT, Navis G, et al. Tissue distribution of ACE2 protein, the functional receptor for SARS coronavirus. A first step in understanding SARS pathogenesis. J Pathol 2004;203:631-7.

29. Cheng H, Wang Y, Wang GQ. Organ-protective effect of angiotensin-converting enzyme 2 and its effect on the prognosis of COVID-19. J Med Virol 2020; doi: 10.1002/jmv.25785.

30. Wrapp D, Wang N, Corbett KS, Goldsmith JA, Hsieh CL, et al. Cryo-EM structure of the 2019-nCoV spike in the prefusion conformation. Science 2020;367:1260-3.

31. Shang J, Ye G, Shi K, Wan Y, Luo C, et al. Structural basis of receptor recognition by SARS-CoV-2. Nature 2020;581:221-4.

32. Ou X, Liu Y, Lei X, Li P, Mi D, et al. Characterization of spike glycoprotein of SARS-CoV-2 on virus entry and its immune crossreactivity with SARS-CoV. Nat Commun 2020;11:1620.

33. Hoffmann M, Kleine-Weber H, Schroeder S, Kruger N, Herrler T, et al. SARS-CoV-2 cell entry depends on ACE2 and TMPRSS2 and is blocked by a clinically proven protease inhibitor. Cell 2020;181:271-80.e8. 
34. Butowt R, Bilinska K. SARS-CoV-2: olfaction, brain infection, and the urgent need for clinical samples allowing earlier virus detection. ACS Chem Neurosci 2020; doi: 10.1021/acschemneuro.0c00172.

35. Olender T, Keydar I, Pinto JM, Tatarskyy P, Alkelai A, et al. The human olfactory transcriptome. BMC Genomics 2016;17:619.

36. Sungnak W, Huang N, Bécavin C, Berg M; HCA Lung Biological Network. SARS-CoV-2 entry genes are most highly expressed in nasal goblet and ciliated cells within human airways. Nat Med 2020; doi: 10.1038/s41591-020-0868-6.

37. Moberly AH, Schreck M, Bhattarai JP, Zweifel LS, Luo W, et al. Olfactory inputs modulate respiration-related rhythmic activity in the prefrontal cortex and freezing behavior. Nat Commun 2018;9:1528.

38. Bao L, Gao H, Deng W, Lv Q, Yu H, et al. Transmission of SARS-CoV-2 via close contact and respiratory droplets among hACE2 mice. J Infect Dis 2020; doi: 10.1093/infdis/jiaa281.

39. Li YC, Bai WZ, Hirano N, Hayashida T, Hashikawa T. Coronavirus infection of rat dorsal root ganglia: ultrastructural characterization of viral replication, transfer, and the early response of satellite cells. Virus Res 2012;163:628-35.

40. Li YC, Bai WZ, Hirano N, Hayashida T, Taniguchi T, et al. Neurotropic virus tracing suggests a membranous-coating-mediated mechanism for transsynaptic communication. J Comp Neurol 2013;521:203-12.

41. Gonzalez JM, Gomez-Puertas P, Cavanagh D, Gorbalenya AE, Enjuanes L. A comparative sequence analysis to revise the current taxonomy of the family Coronaviridae. Arch Virol 2003;148:2207-35.

42. Palasca O, Santos A, Stolte C, Gorodkin J, Jensen LJ. TISSUES 2.0: an integrative web resource on mammalian tissue expression. Database (Oxford) 2018;2018.

43. Rossi A. Imaging of acute disseminated encephalomyelitis. Neuroimaging Clin N Am 2008;18:149-61; ix.

44. De Clercq E, Li G. Approved antiviral drugs over the past 50 years. Clin Microbiol Rev 2016;29:695-747.

45. Leng Z, Zhu R, Hou W, Feng Y, Yang Y, et al. Transplantation of ACE2(-) mesenchymal stem cells improves the outcome of patients with COVID-19 pneumonia. Aging Dis 2020;11:216-28.

46. Das M, Mayilsamy K, Tang X, Han JY, Foran E, et al. Pioglitazone treatment prior to transplantation improves the efficacy of human mesenchymal stem cells after traumatic brain injury in rats. Sci Rep 2019;9:13646. 